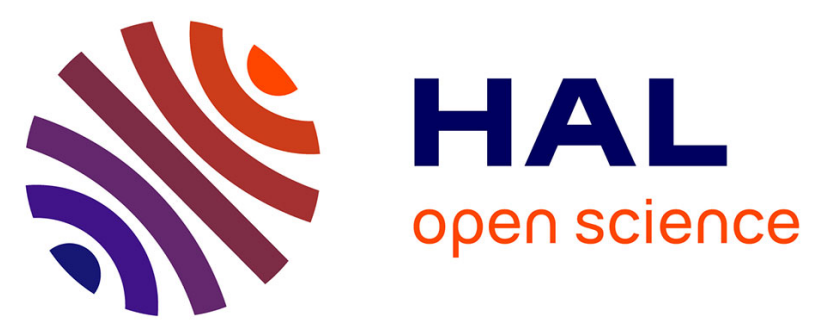

\title{
Should HIV-infected patients be screened for silent myocardial ischaemia using gated myocardial perfusion SPECT?
}

Denis Mariano-Goulart, Jean-Marc Jacquet, Nicolas Molinari, Aurélie Bourdon, Meriem Benkiran, Mélanie Sainmont, Luc Cornillet, Jean-Christophe Macia, Jacques Reynes, Fayçal Ben Bouallègue

\section{To cite this version:}

Denis Mariano-Goulart, Jean-Marc Jacquet, Nicolas Molinari, Aurélie Bourdon, Meriem Benkiran, et al.. Should HIV-infected patients be screened for silent myocardial ischaemia using gated myocardial perfusion SPECT?. European Journal of Nuclear Medicine and Molecular Imaging, 2013, 32 (4), pp.179-187. 10.1007/s00259-012-2262-1 . hal-02548086

\section{HAL Id: hal-02548086 \\ https://hal.umontpellier.fr/hal-02548086}

Submitted on 20 Apr 2020

HAL is a multi-disciplinary open access archive for the deposit and dissemination of scientific research documents, whether they are published or not. The documents may come from teaching and research institutions in France or abroad, or from public or private research centers.
L'archive ouverte pluridisciplinaire HAL, est destinée au dépôt et à la diffusion de documents scientifiques de niveau recherche, publiés ou non, émanant des établissements d'enseignement et de recherche français ou étrangers, des laboratoires publics ou privés. 


\title{
Should HIV-infected patients be screened for silent myocardial ischaemia using gated myocardial perfusion SPECT?
}

\author{
Denis Mariano-Goulart • Jean-Marc Jacquet • Nicolas Molinari • \\ Aurélie Bourdon - Meriem Benkiran • Mélanie Sainmont • \\ Luc Cornillet • Jean-Christophe Macia • Jacques Reynes • \\ Fayçal Ben Bouallègue
}

\begin{abstract}
Purpose A higher prevalence of cardiovascular risk factors (CRFs) in HIV-infected patients, together with chronic infection and treatments, has resulted in an increased risk of silent myocardial ischaemia (SMI). The objective of this study was to evaluate whether myocardial SPECT should be used for screening HIV-infected patients with no clinical symptoms of coronary artery disease.

Methods The prevalence of SMI detected by myocardial SPECT was determined in 94 HIV-infected patients with a normal clinical cardiovascular examination in relation to
\end{abstract}

D. Mariano-Goulart • A. Bourdon • M. Benkiran • M. Sainmont • F. Ben Bouallègue

Department of Nuclear Medicine, Montpellier University Hospital, Montpellier, France

J.-M. Jacquet $\cdot$ J. Reynes

Department of Infectious and Tropical Diseases,

Montpellier University Hospital,

Montpellier, France

N. Molinari

Department of Statistics and Epidemiology,

Montpellier University Hospital,

Montpellier, France

L. Cornillet · J.-C. Macia

Department of Cardiology, Montpellier University Hospital,

Montpellier, France

D. Mariano-Goulart $(\bowtie)$

Département de Médecine Nucléaire,

Centre Hospitalier Universitaire Lapeyronie,

371, avenue du Doyen Gaston Giraud,

34295 Montpellier Cedex 5, France

e-mail: d-mariano_goulart@chu-montpellier.fr anthropomorphic parameters, CRFs, inflammatory and HIV infection status, and treatment.

Results Coronary artery disease was detected in nine patients (eight with ischaemia, one with myocardial infarction), corresponding to $9.6 \%$ positivity. All but two of the scintigraphic diagnoses of ischaemia were confirmed by coronarography. Univariate analysis revealed that the overall number of CRFs and the combination of gender and age were associated with a diagnosis of SMI $(p<0.05)$. According to multivariate analysis, the only independent parameter significantly associated with the scintigraphic diagnosis of SMI was the combination of gender and age $(p=0.01)$. All the positive myocardial SPECT scans were in men older than 52 years with at least two other CRFs. In this subpopulation of 47 patients, the prevalence of SMI detected by myocardial SPECT reached $19.2 \%$.

Conclusion In male HIV-infected patients older than 52 years and with at least two other CRFs, screening for SMI using myocardial SPECT was about four times more likely to be positive than in the general population. This may motivate physicians to advise these patients to undergo more systematic screening for SMI using this technique.

Keywords AIDS · HIV infection · Silent myocardial ischaemia $\cdot$ Gated SPECT $\cdot$ Myocardial perfusion

\section{Introduction}

Combination antiretroviral therapy has changed the prognosis of HIV-infected patients, reducing HIV-related deaths 
and leading to longer survival. These patients are thus more likely to develop the complications of chronic infection, treatment side effects, and the risk factors associated with HIV infection. Within the last decade, the reasons for morbidity and mortality in HIV-infected patients have become more diverse, with the most frequent non-HIV-related causes of death being non-AIDS cancers, hepatitis $\mathrm{C}$ and cardiovascular diseases $[1,2]$. Although some published results are uncertain or negative [3], numerous epidemiological and clinical studies have highlighted the higher risk of coronary artery disease (CAD) in HIV-infected patients [4-7], motivating the search for biological explanations for this increased risk [2, 6-13]. Several studies have indicated that the HIV infection itself could contribute to atherosclerosis [8-11] and that antiretroviral therapies are associated with adverse effects on lipid levels and metabolism [2, $6,7,12]$. Moreover, both are likely to induce an autonomic sensory neuropathy, which might contribute to the development of silent myocardial ischaemia (SMI) in these patients [13].

However, only a few studies have focused on the exact prevalence of silent myocardial perfusion abnormalities in this specific population. In all these studies [14-20], the tests used to detect SMI were not optimal in terms of sensitivity (rest electrocardiogram [14] or echocardiography [16], simple exercise stress [15], severe narrowing using CT angiography [18]) or not specific to ischaemia (plaques [19], coronary artery calcium [20] or moderate narrowing using CT angiography [17]). Thus, the prevalence found by the former (approximately $11 \%)$ and the latter $(30 \%)$ are likely to be under- and overestimated, respectively. Gated single-photon computed emission tomography myocardial perfusion scintigraphy (SPECT) is more sensitive than stress ECG for the detection of CAD, is useful and cost-effective for identifying patients in need of coronary angiography, and provides independent and incremental information for predicting cardiac events $[21,22]$. However, this modality has been used in only one study, which showed no evidence of an increased risk for SMI in young $\mathrm{HIV}$-infected patients receiving highly active antiretroviral therapy and showing a high prevalence of dyslipidaemia and an alteration in circulating markers of inflammation [23].

In this study, we sought to determine whether we could reproduce this finding, which seems to conflict with the results obtained with less sensitive techniques for evaluating SMI in HIV-infected patients. We thus evaluated the utility of myocardial SPECT in the detection of SMI, together with other traditional or AIDS-specific cardiovascular risk factors, in a more heterogeneous population of HIV-infected patients in order to try to optimize a screening procedure for routine clinical settings.

\section{Materials and methods}

Patient population

All patients were prospectively recruited from the Outpatient Department of Infectious and Tropical Diseases of Montpellier University Hospital between November 2009 and January 2012. All gave informed consent prior to study inclusion. During this period, all HIV-infected patients with cardiovascular risk factors but no clinical symptoms of CAD were referred to the Cardiology Department for cardiovascular risk stratification. Patients with no cardiac history, normal clinical cardiac examination, normal resting ECG and normal resting echocardiography were systematically considered for myocardial SPECT, according to the guidelines and indications of this imaging technique [24]. Five patients referred to the cardiology department were excluded from the study because of an abnormal electrocardiogram (three patients had pathological Q waves and one had negative $\mathrm{T}$ waves) or in one patient because of a history of coronary dilation. Thus, 94 patients ( 82 male, 12 female; age $55 \pm 8$ years) were prospectively included in the study. The anthropomorphic characteristics of this population are given in Table 1 . The distribution of traditional cardiovascular risk factors in this population is detailed in Table 2. Table 3 summarizes the characteristics of the population that are linked to chronic HIV infection, its treatment and the presence of coinfections.

\section{Myocardial gated-SPECT studies}

All subjects underwent a 1-day combined dipyridamole $(0.75 \mathrm{mg} / \mathrm{kg})$ exercise stress test followed $3 \mathrm{~h}$ later by a rest myocardial perfusion SPECT study. Acquisitions were performed $15 \mathrm{~min}$ after intravenous administration of ${ }^{99 \mathrm{~m}} \mathrm{Tc}-$ tetrofosmin $(3.7 \mathrm{MBq} / \mathrm{kg}$ ) for the stress study and $45 \mathrm{~min}$ after intravenous administration of ${ }^{99} \mathrm{~m}$ Tc-tetrofosmin $(11 \mathrm{MBq} / \mathrm{kg})$ for the rest study [25]. When stress data were strictly normal (normal exercise stress test, normal gated

Table 1 Anthropomorphic characteristics of the population

\begin{tabular}{lc}
\hline Characteristic & Value \\
\hline Age (years, mean $\pm \mathrm{SD})$ & $55 \pm 8$ \\
Male, $n(\%)$ & $82(87)$ \\
Female, $n(\%)$ & $12(13)$ \\
Weight $(\mathrm{kg}$, mean $\pm \mathrm{SD})$ & $73 \pm 13$ \\
Height $(\mathrm{cm}$, mean $\pm \mathrm{SD})$ & $174 \pm 7$ \\
Body mass index $\left(\mathrm{kg} / \mathrm{cm}^{2}\right.$, mean $\left.\pm \mathrm{SD}\right)$ & $24 \pm 4$ \\
Waist circumference $(\mathrm{cm}$, mean $\pm \mathrm{SD})$ & $96 \pm 15$ \\
Hip measurement $(\mathrm{cm}$, mean $\pm \mathrm{SD})$ & $95 \pm 10$ \\
Waist-to-hip ratio $($ mean $\pm \mathrm{SD})$ & $1.00 \pm 0.08$ \\
\hline
\end{tabular}


Table 2 Cardiovascular risk factors in the population

\begin{tabular}{|c|c|}
\hline Risk factor & Value \\
\hline Men older than 50 years, $n(\%)$ & $63(67)$ \\
\hline Women older than 60 years, $n(\%)$ & $5(5)$ \\
\hline Cigarette smoking, $n(\%)$ & $60(64)$ \\
\hline $\begin{array}{l}\text { Hypertension }(\geq 140 / 90 \mathrm{mmHg} \text { or } \\
\text { antihypertensive medication), } n(\%)\end{array}$ & $37(39)$ \\
\hline Treated type 2 diabetes, $n(\%)$ & $12(13 \%)$ \\
\hline $\begin{array}{l}\text { Glycated haemoglobin in patients } \\
\text { with diabetes }(\%, \text { mean } \pm \text { SD) }\end{array}$ & $6.3 \pm 1.7$ \\
\hline $\begin{array}{l}\text { Dyslipidaemia (medication or LDL } \\
>1.3 \mathrm{~g} / \mathrm{L} \text { and } \mathrm{HDL}<0.6 \mathrm{~g} / \mathrm{L}), n(\%)\end{array}$ & $72(76)$ \\
\hline $\begin{array}{l}\text { HDL cholesterol in patients with } \\
\text { dyslipidaemia }(\mathrm{g} / \mathrm{L}, \text { mean } \pm \mathrm{SD})\end{array}$ & $0.45 \pm 0.19$ \\
\hline $\begin{array}{l}\text { LDL cholesterol in patients with } \\
\text { dyslipidaemia }(\mathrm{g} / \mathrm{L}, \text { mean } \pm \mathrm{SD})\end{array}$ & $1.30 \pm 0.47$ \\
\hline $\begin{array}{l}\text { Triglycerides in patients with } \\
\text { dyslipidaemia }(\mathrm{g} / \mathrm{L}, \text { mean } \pm \mathrm{SD})\end{array}$ & $1.55 \pm 0.87$ \\
\hline $\begin{array}{l}\text { Family history of premature coronary } \\
\text { heart disease, } n(\%)\end{array}$ & $23(24)$ \\
\hline \multicolumn{2}{|c|}{ Number of cardiovascular risk factors, $n(\%)$} \\
\hline One & $3(3)$ \\
\hline Two & $22(23)$ \\
\hline Three & $53(56)$ \\
\hline Four & $15(16)$ \\
\hline Five & $1(1)$ \\
\hline
\end{tabular}

stress perfusion data without left ventricular dilation nor decreased ejection fraction), no rest acquisition was performed. Both acquisitions were performed in the prone position using a dual-headed Infinia Hawkeye I gammacamera (GE Healthcare, Chalfont St. Giles, UK) in a $90^{\circ}$ configuration, with low-energy high-resolution parallelhole collimators. Gated tomographic perfusion scintigraphy was performed with the following acquisition parameters [26]: $6^{\circ}$ per step (15 steps over $90^{\circ}$ per head) for $180^{\circ}, 40 \mathrm{~s}$ acquisition per step, $10 \% \mathrm{R}-\mathrm{R}$ interval acceptance window, eight gated intervals, and $64 \times 64$ matrix size (pixel size 5.5-6.6 mm). With these acquisition parameters, the examination time was $12 \mathrm{~min}$ for patients with regular pacing. Images were reconstructed using a filtered back-projection algorithm (Butterworth filter, order 4 and cut-off frequency 0.25/ $\mathrm{cm}$ for stress studies, order 10 and cut-off frequency $0.4 / \mathrm{cm}$ for rest studies), and short-axis, horizontal longaxis and vertical long-axis sections were obtained.

Two experienced nuclear medicine physicians analysed the images in terms of defect number and severity. The myocardial perfusion bull's eye images were divided into 20 segmental regions. Each region was scored independently using a five-point model depending on the mean segmental activity (MSA) expressed as a ratio of the maximal myocardial activity $(0 \mathrm{MSA} \geq 70 \% ; 1 \mathrm{MSA} \leq 50$ to $<70 \% ; 2$ MSA $\leq 30$ to $<50 \%$; 3 MSA $\leq 10$ to $<30 \%$; 4
MSA <10 \%). Inside a segment, hypoperfusion was considered significant if the mean activity in the segment was below $70 \%$ of the maximal myocardial activity. The 20 segmental scores were summed using the stress and rest studies to derive summed stress scores, summed rest scores and summed difference scores [26]. Stress gated myocardial SPECT with a summed stress score lower than 3, normal stress wall thickening and normal left ventricular ejection fraction on gated data were regarded as normal studies, and these patients did not undergo the rest study [27].

Ischaemia was defined as a reversible perfusion defect (summed difference scores $\geq 3$ ) and necrosis as a fixed significant defect with corresponding abnormal wall thickening. Fixed defects with normal rest wall thickening in the same segment were regarded as artefacts.

A coronary angiography was proposed for all patients with reversible perfusion defects, except for one patient who had haemophilia. Only one patient refused to undergo both coronary angiography and stress echocardiography.

Statistical analysis

The cardiovascular risk factors used in the statistical analysis included age and gender (male $>50$ years or female

Table 3 HIV infection-related characteristics of the population

\begin{tabular}{ll}
\hline Characteristic & Value \\
\hline Lipoatrophy, $n(\%)$ & $35(37)$ \\
Lipohypertrophy, $n(\%)$ & $23(24)$ \\
Neuropathy, $n(\%)$ & $9(10)$ \\
Cytomegalovirus coinfection, $n(\%)$ & $4(4)$ \\
Hepatitis C virus coinfection, $n(\%)$ & $16(17)$ \\
CRP $>5$ mg/L, $n(\%)$ & $14(15)$ \\
Known duration of HIV infection (years) & $16 \pm 7$ \\
Duration of antiretroviral treatment (years) & $12 \pm 6$ \\
CD4 count (cells/mm ${ }^{3}$, mean \pm SD) & $555 \pm 261$ \\
Viral load (more than 20 copies/mL, $n(\%))$ & $18(19)$ \\
CDC classification, $n(\%)$ & \\
Stage A & $44(47)$ \\
Stage B & $17(18)$ \\
Stage C & $33(35)$ \\
Antiretroviral treatment, $n(\%)$ & \\
Nucleotide reverse transcriptase inhibitor & $13(14)$ \\
Non-nucleotide reverse transcriptase inhibitor & $63(67)$ \\
Entry inhibitor & $7 \pm 5$ \\
Integrase inhibitor & \\
Protease inhibitor & $31(33)$ \\
Duration of protease inhibitor treatment & $1(1)$ \\
(years, mean \pm SD) & \\
\hline & \\
\hline
\end{tabular}

$C D C$ Centers for Disease Control and Prevention. 
$>60$ years), smoking (except if smoking cessation $>3$ years ago), hypertension (multiple measures of blood pressure $\geq 140 / 90 \mathrm{mmHg}$ or antihypertensive medication), treated diabetes, dyslipidaemia (LDL cholesterol $>1.3 \mathrm{~g} / \mathrm{L}$ and HDL cholesterol $<0.6 \mathrm{~g} / \mathrm{L}$ or medication) or family history of premature coronary heart disease (occurring in a male or female first-degree relative $<55$ or $<65$ years of age, respectively). The other clinical and biological patient characteristics in the statistical model were anthropomorphic parameters (sex, age, weight, height, body mass index, waist and hip circumferences, waist-to-hip ratio), Centers for Disease Control and Prevention (CDC) classification [28], occurrence of lipohypertrophy, lipoatrophy, or HIV-associated neuropathy, occurrence of coinfections, duration of HIV infection, antiretroviral therapy and protease inhibitor (PI) medication, viral load and CD4 count, and classes of antiretroviral therapies.

The distributions of the clinical data are characterized in terms of the means \pm standard deviation. Univariate associations between these parameters and the detection of SMI by myocardial SPECT were evaluated using Fisher's exact test, the chi-squared test, Student's $t$ test or Wilcoxon's test, as appropriate. The odds ratios of all parameters characterizing the population were evaluated. Independent covariates associated with the diagnosis of SMI with a conservative $p$ value of $<0.25$ in the univariate analysis were subsequently tested in a multivariate logistic analysis. A stepwise procedure was used to select covariates in the final model.

In order to identify the subpopulation containing all patients in whom SMI was detected, we looked for a predictive classification rule with a sensitivity of $100 \%$ for the prediction of a positive scintigraphic screening for myocardial ischaemia. Among the models with perfect sensitivity, we chose the rule with optimal specificity.

\section{Results}

Of the 94 asymptomatic patients who were screened, 80 $(85.1 \%)$ had normal stress tests and normal myocardial SPECT. Five patients $(5.3 \%)$ had an abnormal combined dipyridamole exercise stress test but normal myocardial SPECT data. Three of these patients (one a 53-year-old woman, and two men 66 and 68 years old, three cardiovascular risk factors) had no chest pain during exercise but significant horizontal ST segment depression appearing on the ECG during the stress test. These three patients were not treated and had no adverse cardiovascular events over 10 months, 9 months and 2 years of follow-up, respectively. Two men (50 and 59 years old with four and three cardiovascular risk factors respectively) had both chest pain and ECG changes during the stress test, but normal myocardial SPECT. Both underwent coronary angiography, which ruled out any significant CAD. As a consequence, the five patients with abnormal exercise stress but normal myocardial SPECT images were false-positive in the stress test but true negative on myocardial SPECT.

Nine patients $(9.6 \%$ of the whole population, age $59 \pm$ 7 years) had abnormal myocardial SPECT (Table 4). Six of them had normal exercise stress tests (patients 1-6), two had ECG changes (patients 7 and 8) and one had both ECG changes and chest pain during the exercise stress test (patient 9). One of these nine patients had a scintigraphic pattern of unknown inferior myocardial infarction. The myocardial SPECT data showed significant reversible stress myocardial defects in eight patients. Coronary angiography could not be performed in two of these patients (one patient refused further investigations, and coronary angiography was not performed in the second patient because of an increased iatrogenic risk due to haemophilia). These two patients were treated medically and had no cardiovascular events during 21 and 28 months of follow-up. Six patients

Table 4 Characteristics of the patients in whom silent CAD was detected using myocardial SPECT

\begin{tabular}{lccll}
\hline Patient & Summed stress score & Summed difference score & Myocardial SPECT diagnosis & Coronary angiography \\
\hline 1 & 16 & 7 & Septal ischaemia and inferior necrosis & Impossible (haemophilia) \\
2 & 6 & 5 & Inferior ischaemia & Patient refusal \\
3 & 3 & 0 & Inferior necrosis & Not necessary (no ischaemia) \\
4 & 4 & 3 & Inferior lateral ischaemia & Circumflex artery $50 \%$ \\
5 & 7 & 3 & Inferior lateral ischaemia & First diagonal branch $50 \%$ \\
6 & 5 & 5 & Anterior ischaemia & Left anterior descending artery $100 \%$ \\
7 & 24 & 5 & Antero-septal ischaemia & Left anterior descending artery and right \\
9 & 10 & 3 & Apical ischaemia & coronary artery $100 \%$ circumflex artery $80 \%$ \\
& & & & marginal branch $90 \%$ \\
\hline
\end{tabular}


underwent coronary angiography. Severe coronary lesions in territories consistent with the SPECT findings were found in three patients and intermediate lesions $(50 \%$ reduction in coronary diameter) were found in the three other patients. All patients with a coronary diameter reduction greater than $80 \%$ had changes in ECG and/or chest pain during the stress test.

In the univariate analysis (Tables 5 and 6) the overall number of cardiovascular risk factors and the combination of gender and age (male $>50$ or female $>60$ years) were associated with a diagnosis of SMI $(p<0.05)$. Body mass index and related parameters, high systolic blood pressure, triglyceride levels in patients with high LDL and low HDL cholesterol levels, family history of premature coronary heart disease, and medications including non-nucleotide reverse transcriptase inhibitors or PI were also associated with a diagnosis of SMI $(p<0.25)$ and tested in a multivariate analysis.

In the multivariate analysis, the only significant independent parameter associated with the scintigraphic diagnosis of SMI was the combination of gender and age ( $p=0.01$ for male $>50$ or female $>60$ years). A simple tendency was found for the association with the overall number of other cardiovascular risk factors $(p=0.07)$. The best multivariate model that predicted a diagnosis of SMI in all affected patients included male gender, age and the number of cardiovascular risk factors as a priori predictive factors. All the positive myocardial SPECT were in men older than 52 years having at least two other cardiovascular risk factors (i.e. two factors among smoking, hypertension, diabetes, dyslipidaemia or family history of premature CAD). This subpopulation of 47 patients (i.e. $50 \%$ of the entire study population) was characterized by an age of $59 \pm 5$ years. Besides age and gender, the number of cardiovascular risk factors in these 47 patients was two in 37 patients, three in nine patients and four in one patient. The prevalence of SMI detected in this subpopulation by myocardial SPECT was $19.15 \%$. The sensitivity and negative predictive value of being a man older than 52 years with two other cardiovascular risk factors for the scintigraphic detection of SMI by myocardial SPECT was $100 \%$ (Table 7).

\section{Discussion}

Highly active antiretroviral therapy has greatly reduced mortality and morbidity in HIV-infected patients but is known to have metabolic side effects, including lipodystrophy, dyslipidaemia and diabetes. In a review of 15 studies, Graham found the prevalence of lipodystrophy to be greater than $60 \%$ after 1 year of PI treatment and hypothesized that PI causes this syndrome by impairing the conversion of retinoic acid to cis-9-retinoic acid and inhibiting low-density lipoprotein receptor-related protein [29]. This
Table 5 Results of the univariate analysis a Parameters associated with an abnormal myocardial SPECT included in the multivariate analysis.

\begin{tabular}{llc}
\hline Anthropomorphic characteristic/cardiovascular risk factor & Odds ratio $(95 \% \mathrm{CI})$ & $p$ value \\
\hline Weight & $1.04(0.99-1.10)$ & $0.10^{\mathrm{a}}$ \\
Height & $0.99(0.89-1.10)$ & 0.86 \\
Body mass index & $1.17(0.99-1.39)$ & $0.06^{\mathrm{a}}$ \\
Waist circumference & $1.04(1.00-1.10)$ & $0.08^{\mathrm{a}}$ \\
Hip measurement & $1.07(0.97-1.17)$ & $0.16^{\mathrm{a}}$ \\
Male older than 50 years or female older than 60 years & $1.44(1.16-1.78)$ & $0.001^{\mathrm{a}}$ \\
Cigarette smoking & $1.15(0.27-4.92)$ & 0.85 \\
Pack years & $1.05(0.95-1.16)$ & 0.36 \\
Hypertension ( $\geq 140 / 90$ mmHg or medication) & $3.48(0.81-14.92)$ & $0.09^{\mathrm{a}}$ \\
Systolic pressure & $1.03(0.99-1.08)$ & $0.13^{\mathrm{a}}$ \\
Diastolic pressure & $1.02(0.96-1.08)$ & 0.50 \\
Fasting blood sugar level & $1.01(0.59-1.74)$ & 0.97 \\
Treated type 2 diabetes & $2.14(0.39-11.78)$ & 0.38 \\
Glycated haemoglobin in patients with diabetes & $0.23(0.01-3.92)$ & 0.31 \\
Dyslipidaemia (medication or LDL $>1.3$ and HDL $<0.6 \mathrm{~g} / \mathrm{L})$ & $2.63(0.31-22.23)$ & 0.38 \\
HDL cholesterol level (dyslipidaemic patients) & $0.83(0.02-39.54)$ & 0.92 \\
LDL cholesterol level (dyslipidaemic patients) & $0.39(0.05-3.20)$ & 0.38 \\
Triglyceride level (dyslipidaemic patients) & $0.41(0.12-1.39)$ & $0.15^{\mathrm{a}}$ \\
Family history of premature coronary heart disease & $0.14(0.00-1.50)$ & $0.11^{\mathrm{a}}$ \\
Number of cardiovascular risk factors & $3.67(1.24-10.85)$ & $0.02^{\mathrm{a}}$ \\
Number of cardiovascular risk factors except gender and age & $1.95(0.71-5.42)$ & $0.21^{\mathrm{a}}$ \\
\hline
\end{tabular}


Table 6 Results of the univariate analysis

$C D C$ Centers for Disease Control and Prevention.

${ }^{\mathrm{a}}$ Parameters associated with an abnormal myocardial SPECT included in the multivariate analysis.

\begin{tabular}{llc}
\hline Population characteristics in relation to HIV infection & Odds ratio $(95 \% \mathrm{CI})$ & $p$ value \\
\hline Lipoatrophy & $1.39(0.35-5.58)$ & 0.64 \\
Lipohypertrophy & $2.30(0.46-11.44)$ & 0.31 \\
Neuropathy & $0.43(0.00-5.16)$ & 0.59 \\
Cytomegalovirus coinfection & $0.95(0-15.5)$ & 1.00 \\
Hepatitis C virus coinfection & $0.58(0.07-5.02)$ & 0.62 \\
CRP & $0.89(0.67-1.19)$ & 0.43 \\
Known duration of HIV infection & $0.99(0.89-1.10)$ & 0.83 \\
Duration of anti-retroviral treatment & $1.00(0.88-1.13)$ & 0.96 \\
CD4 count & $1.00(0.99-1.00)$ & 0.33 \\
Viral load: more than 20 copies/mL & $0.99(0.97-1.02)$ & 0.59 \\
Stage C (CDC classification) & $0.50(0.10-2.53)$ & 0.40 \\
Nucleotide reverse transcriptase inhibitor & $0.95(0.11-8.47)$ & 0.96 \\
Non-nucleotide reverse transcriptase inhibitor & $0.23(0.03-1.92)$ & $0.17^{\mathrm{a}}$ \\
Entry inhibitor & $2.96(0.00-366.20)$ & 1.00 \\
Integrase Inhibitor & $1.92(0.35-10.46)$ & 0.45 \\
Protease inhibitor & $0.35(0.09-1.42)$ & $0.14^{\mathrm{a}}$ \\
Duration of protease inhibitor treatment & $1.10(0.88-1.38)$ & 0.38 \\
\hline
\end{tabular}

prevalence is similar to that observed in the present study $(55 \%)$, in which more than two-thirds of the patients were treated with PI. Hyperlipidaemia is also more frequent in these patients than in matched control subjects, with a prevalence of about one-third in published studies, as is diabetes, with a prevalence of about $7 \%$ in HIV-infected patients under highly active antiretroviral therapy [30]. The population of the present study, which was recruited from a university hospital, showed a higher proportion of patients with diabetes (13\%) and hypercholesterolaemia (76\%) than the general population of HIV-infected patients. These glucose and lipid metabolic anomalies are known to be causal factors in the development and acceleration of atherogenesis. Last, chronic inflammation (due to HIV or coinfections), together with the adverse effects of nucleoside analogue treatment, is known to induce an autonomic sensory neuropathy that might contribute to the development of SMI in HIV-infected patients [13].

The prevalence of SMI has been the focus of many studies in healthy subjects and is less than $5 \%$ of the total population [31, 32]. Systematic screening of the whole population is thus not justified from an economic point of view. However, as over a quarter of myocardial infarctions go unrecognized and half of them cause no symptoms at all [33], it is important to determine the measurable factors associated with an increased prevalence of SMI. Classical cardiovascular risk factors such as age, gender, smoking, hypertension, and family history of CAD are known to be strong predictors of SMI [34]. Among them, ageing in particular appears to be most important. The prevalence of exercise-induced silent ischaemia has been found to increase more than sevenfold from $2 \%$ in the fifth and sixth decades to more than $15 \%$ in the ninth decade [34, 35]. Similarly, in a prospective, population-based cohort study, Sigurdsson et al. found that the prevalence of unrecognized myocardial infarction increases from nearly undetectable in those younger than 40 years to more than $5 \%$ in patients in the seventh decade [36]. Ageing and the higher frequency of certain cardiovascular risk factors in HIV-infected patients, such as smoking [12], metabolic anomalies, and the autonomic sensory neuropathy induced by both chronic infection and the adverse
Table 7 Sensitivity, specificity, and negative and positive predictive values of being a man older than 52 years with two other cardiovascular risk factors for the scintigraphic detection of SMI

\begin{tabular}{lccc}
\hline & Positive SPECT & Negative SPECT & \\
\hline $\begin{array}{l}\text { Men }>52 \text { years of age and } \\
\text { two cardiovascular risk } \\
\text { factors }\end{array}$ & 9 & 38 & $\begin{array}{c}\text { Positive predictive } \\
\text { value } 19.15 \%\end{array}$ \\
$\begin{array}{l}\text { Others } \\
\text { Sensitivity } 100 \%\end{array}$ & Specificity $55.3 \%$ & $\begin{array}{c}\text { Negative predictive } \\
\text { value } 100 \%\end{array}$ \\
& 0 & & \\
\hline
\end{tabular}


effects of highly active antiretroviral therapy, are likely to increase the prevalence of SMI in this population.

The mechanisms underlying the potentially increased cardiovascular risk in HIV-treated patients are beginning to be understood [2, 37], but very few studies have been dedicated to the clinical measurement of SMI prevalence. Using electrocardiograms at rest in a large cohort of asymptomatic HIV-infected patients, Carr et al. found ECG evidence of ischaemic heart disease in $11 \%$, the predominant determinants of risk being older age and current hypertensive therapy [14]. The same prevalence was reported by Duong et al. using exercise stress testing in a smaller cohort of HIV-infected patients who had been receiving highly active antiretroviral therapy for at least 1 year [15]. In that study, age, central fat accumulation and cholesterol level were the independent variables associated with the detection of SMI. Last, using echocardiography at rest and exercise testing, Schuster et al. found more frequent left ventricular systolic or diastolic dysfunctions and a higher pulmonary artery pressure in HIV-infected patients than in age-matched healthy subjects, but no patient with SMI [16].

Using coronary computed tomography angiography, d'Ettorre et al. found luminal coronary narrowing exceeding $50 \%$ in $29 \%$ of a small cohort of asymptomatic HIVinfected subjects in whom age was the only independent variable associated with the narrowing [17]. With the same imaging modality, Lo et al. found a $6.5 \%$ prevalence of luminal coronary narrowing greater than $70 \%$ in young HIV-infected men with longstanding HIV disease [18]. Similarly, in HIV-infected cardiovascularly asymptomatic African Americans on long-term antiretroviral therapy, Lai et al. found an overall $30 \%$ prevalence rate of coronary plaques [19]. On the other hand, Talwani et al. quantified coronary artery calcium using electron beam computed tomography and found no difference between HIV-infected patients and controls [20]. The tests in these studies [14-20] to detect SMI were not optimal in terms of sensitivity (rest electrocardiogram or echocardiography, simple exercise stress, severe narrowing using computed tomography angiography) or not specific for ischaemia (plaques or moderate narrowing using computed tomography angiography). In similar situations, such as screening diabetic patients for SMI, SPECT has proven to be more sensitive than stress ECG for detecting $\mathrm{CAD}$ and cost-effective for identifying patients who need coronary angiography. Moreover, it provides independent and incremental information for predicting cardiac events [21, 22].

To our knowledge, all but one of the myocardial scintigraphic studies in HIV-infected patients have investigated only endothelial or vasomotor function $[37,38]$ or have investigated a single clinical case [39]. The only clinical study of myocardial perfusion using gated SPECT in HIVinfected patients under highly active antiretroviral therapy is that of Catzin-Kuhlmann et al. and the finding was negative [23]. In that study no difference was found in SMI prevalence in HIV-infected patients compared with an age- and gender-matched group of infection-free subjects, with the prevalence in HIV-infected patients $(4.8 \%)$ being similar to that generally found in studies involving healthy subjects. This result in a significant number of patients (105 subjects in each group) is interesting and surprising in view of the growing importance of cardiac death in the outcome of HIVinfected patients under antiretroviral therapy $[1,2]$. In contrast, we found a greater prevalence of SMI in the population of the present study, but only men older than 52 years having at least two other cardiovascular risk factors were positive on screening (19.2\% of SMI in this subpopulation). This important point explains the apparent discordance between our results and those of Catzin-Kuhlmann, because in their study, the all HIV-infected patients and controls were younger than 47 years. In fact, our results together with those of previously reported studies [14, 15, 17, 23] emphasize that the ageing of HIV-infected patients because of the efficiency of highly active antiretroviral therapy may be more relevant in explaining the increased incidence of SMI than the possible side effects of these medications. Moreover, in the older population of the present study, certain cardiovascular risk factors such as hypertension or current smoking were more frequent (39\% versus $18 \%$ and $64 \%$ versus $34 \%$, respectively). Thus the comparison between the study of Catzin-Kuhlmann et al. and the present study emphasizes the key role of age and gender in the prevalence of SMI in HIV-infected patients.

The present study was designed to evaluate the utility of myocardial SPECT in the detection of SMI among HIVinfected patients. As we did not aim to test whether HIV infection in itself should be considered a cardiovascular risk factor, we did not perform myocardial SPECT on a control population of patients without HIV infection matched for age and other cardiovascular risk factors. However, the comparison between our results and those of Fleg et al. in the Baltimore Longitudinal Study of Aging [35] may give an insight into this question. More smokers were found in the population of the present study compared with the study of Fleg et al. (64\% versus $14 \%$ ), but the frequencies of hypertensive patients, serum cholesterol and fasting plasma glucose levels as well as body mass indexes were similar. In a population of patients without HIV infection, Fleg et al. found that the prevalence of exercise-induced SMI increased with age, from $2 \%$ in the fifth and sixth decade to $15 \%$ in the ninth decade. In our population of HIV-infected patients, all patients except one with positive myocardial SPECT were in the fifth and sixth decade, and the prevalence of SMI was $7.5 \%$ during the fifth decade and $11.5 \%$ during the sixth decade. In comparison with the increase in SMI prevalence with age found by Fleg (Fig. 1 in reference [35]), 
SMI appeared a decade earlier in our population of HIVinfected patients. As the relative risk of smoking for predicting coronary events is between 1.7 and 2.3 depending on the model chosen [35], the difference in smoking habits between the population of Fleg et al. and our HIV-infected patients probably cannot explain alone the higher rate of detection of SMI in HIV-infected patients.

These results support the hypothesis that HIV infection should be regarded in itself as a possible cardiovascular risk factor or, at least, as a situation that is likely to bring forward the adverse effects of traditional cardiovascular risk factors. This hypothesis needs to be confirmed in a larger casecontrol study. In any case, together with the results of Fleg et al. [35], our study showed that before the fifth decade, the prevalence of SMI is very low in HIV-infected patients. From a very practical point of view, this result is important because it means that systematic screening of HIV-infected patients is not justified before the fifth decade, even if further studies confirm that HIV infection in itself can be regarded as a cardiovascular risk factor.

Another limitation of our study was the origin of the population, which was recruited from the outpatient department of infectious and tropical diseases of a university hospital. In comparison with the DAD (data collection on adverse events of anti-HIV drugs) study [40], our study included a higher proportion of patients with cardiovascular risk factors, with more smokers (64\% versus $51.5 \%$ ), more patients with hypertension (39\% versus $8.5 \%$ ), more diabetic patients (13\% versus $2.5 \%$ ), more patients with a BMI of $>30 \mathrm{~kg} / \mathrm{m}^{2}(5.3 \%$ versus $3.5 \%)$, more patients with hypercholesterolaemia (76\% versus $22.2 \%$ ), and more patients with a family history of CAD (24\% versus $11.4 \%$ ). As a consequence, the relatively high prevalence of SMI found in patients older than 52 years with at least two other cardiovascular risk factors may partially reflect the characteristics of this subpopulation of HIV-infected patients. However, this result is very similar to the $18 \%$ prevalence of concordant exercise-induced asymptomatic ST-segment depression on electrocardiography and perfusion defects on myocardial SPECT found by Katzel et al. in men aged 55 to 70 years with no previously known CAD [34]. Thus, the observed increased prevalence of SMI among HIV-infected patients is more likely to have been the consequence of ageing than an effect of chronic infection, HIV-related metabolism changes or highly active antiretroviral therapy. In any case, myocardial SPECT should not be used systematically to screen asymptomatic HIVinfected patients before the fifth decade. In fact, in all subjects, but even more so in HIV-infected patients, a very simple cardiovascular risk factor such as the combination of age and male gender, appears to be essential to discriminate patients who are likely to be positive for SMI on SPECT. The results of the present study should motivate further studies (1) to confirm our preliminary finding on the prevalence of SMI in HIV-infected men older than 50 years and (2) to evaluate the benefits of scintigraphic screening in terms of morbidity and mortality.

\section{Conclusion}

In the asymptomatic population of this study, only male HIV-infected patients older than 52 years with at least two other cardiovascular risk factors were positive for SMI on myocardial SPECT. In this subpopulation, the prevalence of SMI was evaluated as $19 \%$, about fourfold greater than the upper limit for SMI prevalence in subjects without HIV infection. On the other hand, all myocardial SPECT findings were normal for HIV-infected patients without these characteristics.

As combination antiretroviral therapy has led to the longer survival of HIV-infected patients, this result may prompt physicians to advise male patients in this subpopulation to undergo more systematic screening for SMI using myocardial SPECT.

\section{Conflicts of interest None.}

\section{References}

1. Lewden C, May T, Rosenthal E, Burty C, Bonnet F, Costagliola D, et al. Changes in causes of death among adults infected by HIV between 2000 and 2005: the "Mortalite' 2000 and 2005" surveys (ANRS EN19 and mortavic). J Acquir Immune Defic Syndr. 2008;48:590-8.

2. Currier JS. Update on cardiovascular complications in HIV infection. Top HIV Med. 2009;17(3):98-103.

3. Bozzette SA, Ake CF, Tam HK, Chang SW, Louis TA. Cardiovascular and cerebrovascular events in patients treated for human immunodeficiency virus infection. N Engl J Med. 2003;348(8):702-10.

4. Triant VA, Lee H, Hadigan C, Grinspoon SK. Increased acute myocardial infarction rates and cardiovascular risk factors among patients with human immunodeficiency virus disease. J Clin Endocrinol Metab. 2007;92(7):2506-12.

5. Obel N, Thomsen HF, Kronborg G, Larsen CS, Hildebrandt PR, Sørensen HT, et al. Ischemic heart disease in HIV-infected and HIV-uninfected individuals: a population-based cohort study. Clin Infect Dis. 2007;44(12):1625-31.

6. Barbaro G, Di Lorenzo G, Cirelli A, Grisorio B, Lucchini A, Hazra $\mathrm{C}$, et al. An open-label, prospective, observational study of the incidence of coronary artery disease in patients with HIV infection receiving highly active antiretroviral therapy. Clin Ther. 2003;25 (9):2405-18.

7. Holmberg SD, Moorman AC, Williamson JM, Tong TC, Ward DJ, Wood KC, et al. Protease inhibitors and cardiovascular outcomes in patients with HIV-1. Lancet. 2002;360(9347):1747-8.

8. Eugenin EA, Morgello S, Klotman ME, Mosoian A, Lento PA, Berman JW, et al. Human immunodeficiency virus (HIV) infects human arterial smooth muscle cells in vivo and in vitro: implications for the pathogenesis of HIV-mediated vascular disease. Am J Pathol. 2008;172(4):1100-11. 
9. Crowe SM, Westhorpe CL, Mukhamedova N, Jaworowski A, Sviridov D, Bukrinsky M. The macrophage: the intersection between HIV infection and atherosclerosis. J Leukoc Biol. 2010;87(4):589-98.

10. Rose H, Hoy J, Woolley I, Tchoua U, Bukrinsky M, Dart A, et al. HIV infection and high density lipoprotein metabolism. Atherosclerosis. 2008;199(1):79-86.

11. Triant VA, Meigs JB, Grinspoon SK. Association of C-reactive protein and HIV infection with acute myocardial infarction. $\mathrm{J}$ Acquir Immune Defic Syndr. 2009;51(3):268-73.

12. Savès M, Chêne G, Ducimetière P, Leport C, Le Moal G, Amouyel $\mathrm{P}$, et al. Risk factors for coronary heart disease in patients treated for human immunodeficiency virus infection compared with the general population. Clin Infect Dis. 2003;37(2):292-8.

13. Keswani SC, Pardo C, Cherry C, Hoke A, McArthur JC. HIVassociated sensory neuropathies. AIDS. 2002;16:2105-17.

14. Carr A, Grund B, Neuhaus J, El-Sadr WM, Grandits G, Gibert C, et al. Asymptomatic myocardial ischaemia in HIV-infected adults. AIDS. 2008;22(2):257-67.

15. Duong M, Cottin Y, Piroth L, Fargeot A, Lhuiller I, Bobillier M, et al. Exercise stress testing for detection of silent myocardial ischemia in human immunodeficiency virus-infected patients receiving antiretroviral therapy. Clin Infect Dis. 2002;34(4):523-8.

16. Schuster I, Thöni GJ, Edérhy S, Walther G, Nottin S, Vinet A, et al. Subclinical cardiac abnormalities in human immunodeficiency virus-infected men receiving antiretroviral therapy. Am J Cardiol. 2008;101(8):1213-7.

17. d'Ettorre G, Francone M, Mancone M, Ceccarelli G, Ascarelli A, Vullo F, et al. Significant coronary stenosis detected by coronary computed angiography in asymptomatic HIV infected subjects. J Infect. 2012;64(1):82-8.

18. Lo J, Abbara S, Shturman L, Soni A, Wei J, Rocha-Filho JA, et al. Increased prevalence of subclinical coronary atherosclerosis detected by coronary computed tomography angiography in HIVinfected men. AIDS. 2010;16(24(2)):243-53.

19. Lai S, Bartlett J, Lai H, Moore R, Cofrancesco Jr J, Pannu H, et al. Long-term combination antiretroviral therapy is associated with the risk of coronary plaques in African Americans with HIV infection. AIDS Patient Care STDS. 2009;23(10):815-24.

20. Talwani R, Falusi OM, Mendes de Leon CF, Nerad JL, Rich S, Proia LA, et al. Electron beam computed tomography for assessment of coronary artery disease in HIV-infected men receiving antiretroviral therapy. J Acquir Immune Defic Syndr. 2002;30(2):191-5.

21. Mowatt G, Vale L, Brazzelli M, Hernandez R, Murray A, Scott N, et al. Systematic review of the effectiveness and cost-effectiveness, and economic evaluation, of myocardial perfusion scintigraphy for the diagnosis and management of angina and myocardial infarction. Health Technol Assess. 2004;8(30):iii-iv, 1-207.

22. Sharir T, Kang X, Germano G, Bax JJ, Shaw LJ, Gransar H, et al. Prognostic value of poststress left ventricular volume and ejection fraction by gated myocardial perfusion SPECT in women and men: gender-related differences in normal limits and outcomes. J Nucl Cardiol. 2006;13(4):495-506.

23. Catzin-Kuhlmann A, Orea-Tejeda A, Castillo-Martínez L, ColínRamírez E, Asz D, Aguirre VH, et al. Human immunodeficiency virus-infected subjects have no altered myocardial perfusion. Int $\mathrm{J}$ Cardiol. 2007;122:90-2.

24. Hendel RC, Berman DS, Di Carli MF, Heidenreich PA, Henkin RE, Pellikka PA, et al. ACCF/ASNC/ACR/AHA/ASE/SCCT/ SCMR/SNM 2009 appropriate use criteria for cardiac radionuclide imaging. J Am Coll Cardiol. 2009;53(23):2201-29.
25. Philippe L, Merino B, Blaire T, Bailliez A, Casset-Senon D, Levy $\mathrm{M}$, et al. Tetrofosmin early time gated post-stress single-photon emission computed tomography imaging: feasibility and potential benefits. J Nucl Cardiol. 2011;18:62-72.

26. Hesse B, Tägil K, Cuocolo A, Anagnostopoulos C, Bardiés M, Bax J, et al. EANM/ESC procedural guidelines for myocardial perfusion imaging in nuclear cardiology. Eur J Nucl Med Mol Imaging. 2005;32(7):855-97.

27. Duvall WL, Wijetunga MN, Klein TM, Razzouk L, Godbold J, Croft LB, et al. The prognosis of a normal stress-only Tc-99 m myocardial perfusion imaging study. J Nucl Cardiol. 2010;17(3):370-7.

28. 1993 revised classification system for HIV infection and expanded surveillance case definition for AIDS among adolescents and adults. MMWR Recomm Rep. 1992;41(RR-17):1-19.

29. Graham NM. Metabolic disorders among HIV-infected patients treated with protease inhibitors: a review. J Acquir Immune Defic Syndr. 2000;25:S4-11.

30. Carr A, Samaras K, Thorisdottir A, Kaufmann GR, Chisholm DJ, Cooper DA. Diagnosis, prediction and natural history of HIV-1 protease-inhibitor associated lipodystrophy, hyperlipidemia and diabetes mellitus: a cohort study. Lancet. 1999;353:2093-9.

31. Fazzini PF, Prati PL, Rovelli F, Antoniucci D, Menghini F, Seccareccia $\mathrm{F}$, et al. Epidemiology of silent myocardial ischemia in asymptomatic middle-aged men (the ECCIS Project). Am J Cardiol. 1993;72 (18):1383-8.

32. Parmley WW. Prevalence and clinical significance of silent myocardial ischemia. Circulation. 1989;80:68-73.

33. Kannel WB, Abbott RD. Incidence and prognosis of unrecognized myocardial infarction. An update on the Framingham study. N Engl J Med. 1984;311:1144-7.

34. Katzel LI, Sorkin KD, Colman E, Goldberg AP, Busby-Whitehead MJ, Lakatta LE, et al. Risk factors for exercise-induced silent myocardial ischemia in healthy volunteers. Am J Cardiol. 1994;74(9):869-74.

35. Fleg JL, Gerstenblith G, Zonderman AB, Becker LC, Weisfeldt ML, Costa Jr PT, et al. Prevalence and prognostic significance of exercise-induced silent myocardial ischemia detected by thallium scintigraphy and electrocardiography in asymptomatic volunteers. Circulation. 1990;81:428-36.

36. Sigurdsson E, Thorgeirsson G, Sigaldason H, Sigfusson N. Unrecognized myocardial infarction: epidemiology, clinical characteristics, and the prognostic role of angina pectoris. Ann Intern Med. 1995;122:96-102.

37. Kristoffersen US, Wiinberg N, Petersen CL, Gerstoft J, Gutte H, Lebech AM, et al. Reduction in coronary and peripheral vasomotor function in patients with HIV after initiation of antiretroviral therapy: a longitudinal study with positron emission tomography and flow-mediated dilation. Nucl Med Commun. 2010;31(10):874-80.

38. Lebech AM, Kristoffersen US, Wiinberg N, Kofoed K, Andersen $\mathrm{O}$, Hesse $\mathrm{B}$, et al. Coronary and peripheral endothelial function in HIV patients studied with positron emission tomography and flowmediated dilation: relation to hypercholesterolemia. Eur J Nucl Med Mol Imaging. 2008;35:2049-58.

39. Mariano-Goulart D, Ilonca D, Bourdon A. Diagnosis of silent myocardial ischemia during the staging of HIV-associated lymphoma with FDG PET/CT. Clin Nucl Med. 2009;34:731-3.

40. Friis-Moller N, Weber R, Reiss $P$, Thiébaut R, Kirk O, d'Arminio $\mathrm{MA}$, et al. Cardiovascular disease risk factors in HIV patients association with antiretroviral therapy. Results from the DAD study. AIDS. 2003;17:1179-93. 